\title{
Design and Fabrication of Cassava Grating Machine
}

\author{
S. K. Bello ${ }^{1}$, S.B. Lamidi ${ }^{1}$, S.A. Oshinlaja ${ }^{2}$ \\ ${ }^{1}$ Department of Mechanical Engineering, Lagos State Polytechnic, Ikorodu \\ ${ }^{2}$ Department of Civil Engineering, Lagos State Polytechnic, Ikorodu \\ Nigeria
}

\begin{abstract}
The Cassava grating machine that was designed has two modes of operation, it can be powered either electrically or manually. It takes care of power failure problems. The Cassava is fed with the Machine through the hopper made of metal sheet to the granting drum, which rotates at a constant speed. This process grates the cassava into cassava pulp. The chute made up of metal sheet accepts the pulp and sends it out because of its inclination which is operated manually. The efficiency of the machine was found to be $82.7 \%$, which the efficiency of the electrically powered machine was found to be $79.5 \%$. The need for the hygienic processing of cassava, is very important as well as the prevalent conditions in the commercial grating areas of this staple food as it is likely to be affected by food contamination. A home-scale cassava grating machine was designed and fabricated, with machine efficiency, safety factors, and portability all taken into consideration. The grating hopper and drum are modified with the drum having a stainless-steel sheet wrapped around a galvanized mild steel core. The machine runs on a single phase 6.5HP (horse power), electric motor, multiple customers with increased through-put when compared to other available grating machines. The performance efficiency of the grater for fresh cassava samples depends on the results showing significant variation for combination of process parameters. This study carried out the performance and optimization evaluation of single barrel cassava grating machine on selected fresh and stored cassava species. The species were used at different levels of moisture content, $70.4 \% \mathrm{db}$. and $58.4 \% \mathrm{db}$. depicting the average moisture contents obtained for fresh and stored cassava respectively.
\end{abstract}

Key words: Cassava, Chute, Efficiency, Grating, Hopper.

\section{INTRODUCTION}

Nigeria is one of the world-leading producers of cassava with an estimated annual production of 2.6 million tons from an estimated area of $1 \%$ million hectares of land (Agbetoye, 2005) ${ }^{[2]}$. The major problem of cassava is that it is extremely perishable and the harvested tuber must be processed to curb. postharvest losses. According to food and Agriculture Organization (Kolawole, FAO, 2001) ${ }^{[6]}$ the estimated industrial cassava use was approximately, 16 percent of cassava root production and was utilized as an industrial raw material in 2001 in Nigeria. Around the world, cassava is a vital stable food for about 500 million people. Cassava's starching roots produce more food energy permit of land than any other staple crop. It is one of the most valuable staple food source for tens of millions of people in the West African sub-region. Cassava is a very important food crop that is capable of providing food security. However, a lot of problems prevent the development and use of modern equipment for its production. Most of the cassava produced still comes from peasant farmers who depend on manual tools for their field operations and these farmers have made Nigeria the world's largest producer of the crop. An increase in production of cassava to sustain the world food security needs improved machinery to allow its continuous cultivation and processing.

Cassava, scientifically called Manihotesculenta (Agbetoye 2005) ${ }^{[2]}$ and a botanically member of the ManihoruliUssima. It is a starchy, root crop, grown throughout the tropical world. Cassava is second only to the sweet potato as the most important starchy root crop and it is known around the globe for its trade values as starchy crop and food. It has an encouraging future as international substrate for the production of protein by rat and fungal fermentation (Bamiro 2007) ${ }^{[4]}$. Cassava is an important tropical plant serving the following importance, source of industrial starch granules, important in chemical processing of ethanol and other substances, source of flour, peeled roots can be crushed and fermented before frying to produce "semi-dextrin food stuff, among others. (FAOSTAT 2002) ${ }^{[5]}$. Gari is the most popular staple food derived from cassava and it is a creamy-white, granular flour with a slightly fermented flavor a slightly sour taste made from fermented, gelatinized fresh cassava roots (International ritute of Tropical Agriculture (IITA, 2005). 


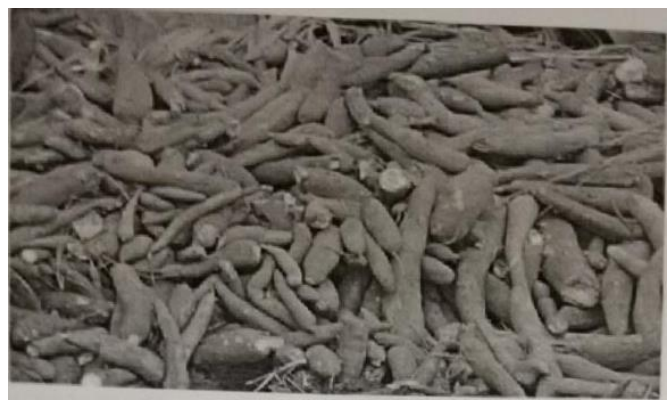

Fig. I Fresh, undamaged cassava roots

The principle of preservation and processing cassava is made by fermentation to remove cyanide and produce the desirable flavor. It is then roasted to destroy enzymes and microorganisms, to drive off cyanide gas, and to dry the product

This study was aimed at alleviating some of these problems encountered by traditional processors by mechanization of cassava processing operation to enhance human capacity.

Systematic interventions in the cassava sector began in the early 1980s with the introduction of high yielding, early bulking varieties resistant to the cassava mosaic disease (CMD) and cassava bacterial blight (CBB), produced at the International Institute for Tropical Agriculture (IITA) in 70s', and the establishment of small-scale processing facilities. At present, approximately half of world production of cassava is in Africa where it is cultivated in around 40 countries, itching through a wide belt from Madagascar in the southeast to Senegal and Cape Verde in northwest. Approximately 75 percent of Africa's cassava output is harvested in Nigeria, the Democratic Republic of Congo. Ghana, Tanzania and Mozambique. Cassava is grown by millions of poor African farmers, many of them women, often on marginal land.

\subsection{Statement of the Problem}

Small farms remain the center of agriculture and rural development. Small scale farming is more prominent to the volume of production than in industrialized farms, particularly in cassava production in the Caraga Region. Thus, a non- availability of locally designed and fabricated machines for cassava processing is a problem

1. the existing machines in the Caraga Region are not automated enough and the open framed designs give unsafe environment for operations;

2. the cassava, grater and presser are mechanically separated and more work is needed during operations.

\subsection{Objectives of the Study}

One of the main causes for the low agricultural productivity in the Philippines especially in the Caraga Region is the lack of appropriate machineries that cater and suit the requirements of small-scale farmers. Hence, some of the small farms are deemed unproductive and ineffective. Thus, this study is aimed at the following objectives:

To develop a machine for cassava, grating and pressing that is electrically powered for rural areas

3. To minimize cassava contamination by using appropriate selection of materials

.4. To combine the cassava grating and pressing mechanisms in one system for continuous operation.

\subsection{Mode of operations}

The single barrel grater was designed in such a way that one electric motor provides the primary motion required to power the machine. This motion produces a torque which is transmitted to the grating barrel via the belt, pulley, shaft, and bearing. The grating barrel is mounted in such a manner as to give a critical gap between it and the rectangular plate attached adjacent to one side of the inlet hopper. This plate, like the grating barrel has an abrasive edge which also helps to ensure proper grating of the product. The single barrel operates in one direction.

(Adejumo 2004) ${ }^{[1]}$ in his design used a wooden grater in which the cassava is forced into a hopper is rubbed against the grater which is powered electrically. An enhanced quantity of cassava can be grated using this method. However, the durability of the grater is low because of its wooden nature

As regards the performance evaluation of cassava graters, not much work has been done beyond testing for the capacity and efficiency of the graters (Ndaliman, 2006) ${ }^{[7] .}$ 
Performance Evaluation and Optimization of Single Barrel Cassava Grating Machine was affected by the specie and the size of the cassava tube. In this study, in-depth study of performance evaluation selected fresh and stored cassava using three cassava species will be carried out followed by scientific design of experiment to obtain optimized conditions.

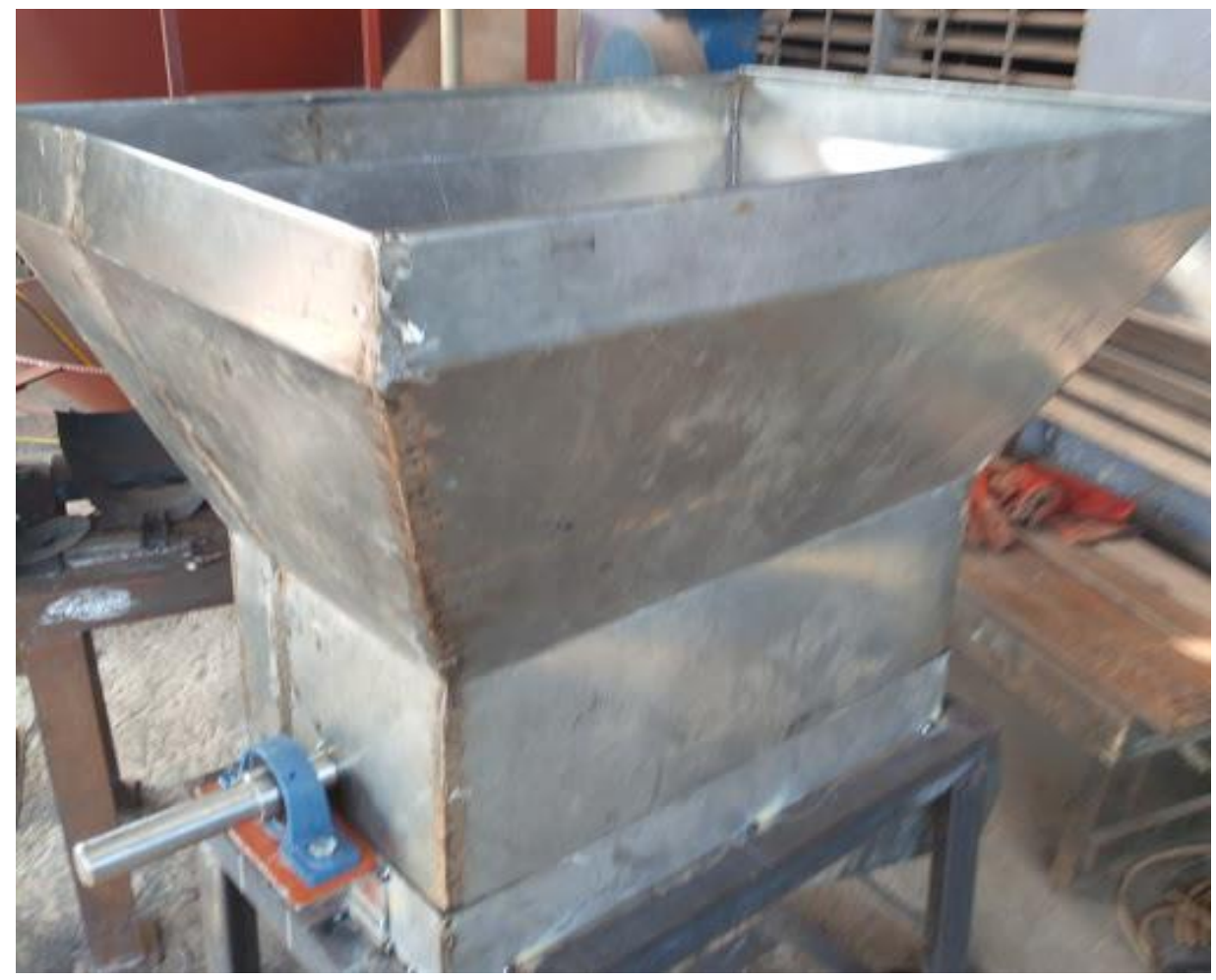

Fig.2, Manually operated cassava grater

\subsection{METHODOLOGY}

The methodology of this research took care of the component design of the electric grating machine, material selection for each component, operating description of the system, engineering drawings and required system assembly as well as the estimated production cost. The identified components to be designed are as folows: hopper, delivery chute, cover, bolt and nut, machine base/frame, grating drum, and shaft.

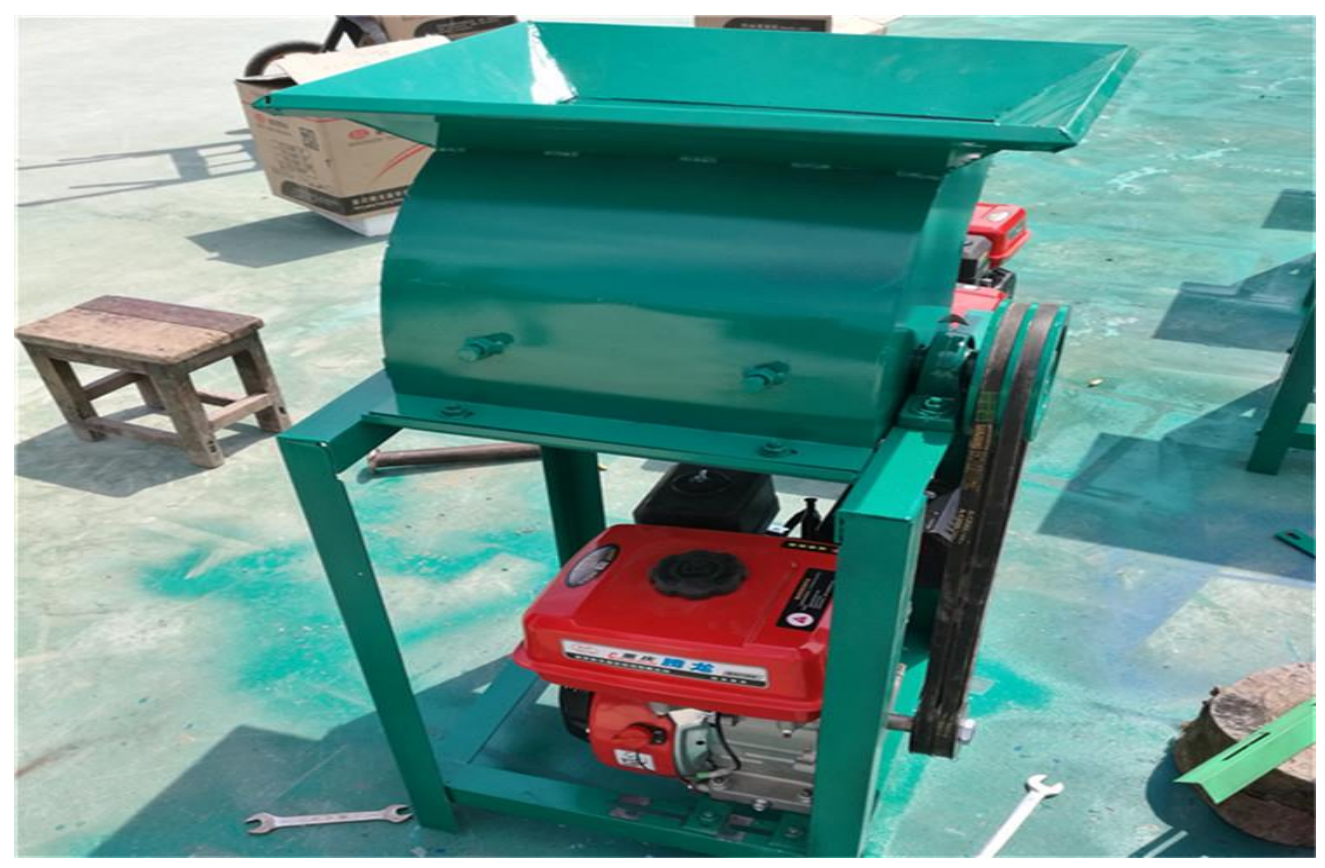

Fig 3: Add figure caption 
The materials to be used for fabrication were selected based on the physical engineering properties with emphasize on consideration for chemical and aesthetic characteristics of the materials. For this project. due to economic considerations and availability of the raw materials. Stainless steel, mild steel was mostly used for body parts and chuck materials while cast iron chosen for pulley.

\subsection{MACHINE COMPONENTS}

Machine Frame: The machine frame supports the other parts of the cassava grating machine, as well as providing stability. It is subjected to the weighs of other members of the machine and also the torque and vibration from the grating drum and motor.

The Hopper: The hopper is the receptacle through which cassava is admitted into machine for grating.

The Grating Unit: This unit consists of the drum, shaft perforated mesh, rolled sheet, circular discs. The drum is held by a shaft passing through the rolled cylindrical sheet and it will be welded in place by circular discs. This drum is then wrapped with the perforated mesh, which are held in position through riveting

Pulley: The pulley, attached to the shaft through the grating drum, is made up of rigid, hard and machinable material. Cast iron was chosen for this purpose as the pulley would be subjected to tension forces from the belt as well as torque and speed variations from the motor.

Table 1 Bill of Materials

\begin{tabular}{|l|l|l|l|}
\hline S/N & \multicolumn{1}{|c|}{ Material } & \multicolumn{1}{|c|}{ Specification } & \multicolumn{1}{|c|}{ Quantity } \\
\hline $\mathbf{1}$ & Metal sheet & Mild steel gauge 14 & 1 full sheet \\
\hline $\mathbf{2}$ & Round plates & Mild steel 170 mm diameter & $1 / 4$ length \\
\hline $\mathbf{3}$ & Angle iron & Mild steel 50 X 50 & 2 full length \\
\hline $\mathbf{4}$ & Shaft & Mild steel 25 mm diameter & $870 \mathrm{~mm}$ long \\
\hline $\mathbf{5}$ & Round pipe & $170 \mathrm{~mm}$ diameter & $480 \mathrm{~mm}$ long \\
\hline $\mathbf{6}$ & Bearing & 6305 & 2 \\
\hline $\mathbf{7}$ & Housing & $39 \mathrm{~mm}$ & 2 \\
\hline $\mathbf{8}$ & Pulley & $750 \mathrm{~mm}$ diameter & 1 \\
\hline $\mathbf{9}$ & Bolts and nuts & M 10 & $1 / 2$ dozen \\
\hline $\mathbf{1 0}$ & Electrode & Gauge 12 & 1 \\
\hline $\mathbf{1 1}$ & Wood & $11 / 2$ & dozen \\
\hline
\end{tabular}

\subsection{DESIGN CALCULATION}

\section{Hopper Design}

The hopper considered is the one with a rectangular cross section.

The volume of which can be obtained as follows:

$=$ L.B.H $\left(\mathrm{m}^{3}\right)$

Where, $\mathrm{V}=$ Volume of hopper; $\mathrm{L}=$ Hopper length; $\mathrm{B}=$ Hopper breath; $\mathrm{H}=$ Hopper height.

The mass of the hopper is given as: P.V (kg)

Where, $\mathrm{p}=$ density of material.

\section{Grating Drum Design}

The grating drum is cylindrical in shape. The volume of the cylinder is given by:

$$
\mathrm{Vc}=\pi \cdot \mathrm{r}^{2} \cdot \mathrm{I}\left(\mathrm{m}^{3}\right)
$$

Where, $\mathrm{Vc}=$ volume of cylinder; $\mathrm{R}=$ radius of cylinder; $\mathrm{L}=$ length of drum. 
International Journal of Advances in Scientific Research and Engineering (ijasre), Vol 6 (10), October -2020

The force acting on the cylinder drum is given as: $\mathrm{F}=\mathrm{V} \cdot \mathrm{p} . \mathrm{g}$

Where, $\mathrm{g}=$ accelerated due to gravity.

\subsection{Shaft design}

The shaft considered has to be rigid while transmitting load under various operating conditions. For solid shaft having little or no axial load, the diameter is given by:

$\mathrm{D}^{3}=16 / \mathrm{TtSs}((\mathrm{KbMb}) 2+(\mathrm{KtMt}) 2)^{1 / 2}$

Where, $\mathrm{Mt}=$ torsional moment

$\mathrm{Mb}=$ bending moment

$\mathrm{Kb}=$ combined shock and fatigue applied to bending moment (1.5),

$\mathrm{Kt}=$ combined shock and fatigue applied to torsional moment (1.0) and

Ss $=$ allowable stress.

For a shaft transmitting power $(\mathrm{kW})$ at a rational speed $(\mathrm{rpm})$ the transmitting is given as:

Mt $=$ Power/Speed

\subsection{Speed Ratio}

The speed ratio of the larger pulley on the machine shaft to the smaller pulley on the electric motor is givens as: NI DI - N2

Where, $\mathrm{NI}=$ speed of electric motor, $\mathrm{N} 2$ = speed of machine driving shaft, $\mathrm{DI}=$ diameter of motor pulley, and D2 = diameter of machine pulley.

\subsection{The Grating Efficiency is given as;}

$\mathrm{Ig}=\mathrm{Wr} / \mathrm{Wf} 100$

Where, $\mathrm{gg}=$ Grating efficiency, $\mathrm{Wr}=$ Total weight recovered, and $\mathrm{Wf}=$ Total weight fed in .

This was obtained for each of the manually operated and electrically powered operations.

pulp exit channels (chute) are in opposite directions.

\subsection{RESULTS AND DISCUSSION}

From the table of results shown below it can be seen clearly that the efficiency of the grater for fresh cassava samples depends on the results showing significant variation for combination of process parameters. Appropriate speed of electric motor of 1500rpm was selected to be able to overcome the load.

Table 2 Results of Design Calculations and Specifications

\begin{tabular}{|c|l|c|}
\hline $\mathbf{S} / \mathbf{N}$ & \multicolumn{1}{|c|}{ Parameters } & Values \\
\hline $\mathbf{1}$ & Volume of Hopper & $0,071232 \mathrm{~m}$ \\
\hline $\mathbf{2}$ & Mass of the Hopper & $555,61 \mathrm{~kg}$ \\
\hline $\mathbf{3}$ & Diameter of Shaft & $23,00 \mathrm{~mm}$ \\
\hline $\mathbf{4}$ & Diameter of selected Shaft & $25,00 \mathrm{~mm}$ \\
\hline $\mathbf{5}$ & Speed of Electric motor & $1500 \mathrm{rpm}$ \\
\hline $\mathbf{6}$ & Speed of the Shaft & $1150 \mathrm{rpm}$ \\
\hline
\end{tabular}

\subsection{CONCLUSION AND RECOMMENDATION}

The design and development of a manually operated cassava grating machine prototype is herewith presented. The prototype grater is shown to be easy to operate at $30-45 \mathrm{rpm}$ to give a product whose quality is as good as that from motorized graters at a throughput of $125-185 \mathrm{~kg} / \mathrm{h}$. The prototype grater is a powerful alternative to the sedentary drudgery and pain-inflicting process 
involved in the traditional grating method. Cassava will be fed into the machine through the hoppers to be made of metal sheet to the granting drum, which will rotate at a constant speed. This process will grate the cassava into cassava pulp. The chute is to be constructed of metal sheet and it will accept the pulp and send it out into storage container. The home use small scale cassava grating machine is designed, fabricated and tested. It was to be effective and efficient and could grate about $158.9 \mathrm{~kg} / \mathrm{hr}$. This machine can be used for home scale domestic applications and it is affordable. Design analysis, materials selection, construction, and performance evaluation of the machine was checked to ascertain functionality. The machine is simple and designed in such a way that it can be easily sported from one point to another. Careful selection of durable and locally sourced raw materials for the fabrication was also taking into consideration. Efficiency, design mechanism (in terms of grating unit), and speed at which the machine rates can be improved upon are some of the areas for future and improved work.

\section{REFERENCES}

1. Adejumo S.O., Construction and Evaluation of an Engine Operated Bur, 1994

2. Agbetoye L.A.S., of and Ogunlowo A.S. (2007) Cassava Mash Dewatering Parameters, International Journal of Food Engineering: Vol. 3: is I, Article 4. httt://www.be ress.com/i' fe/v013/iss 1/art4.

3. Bamiro. O. A-(2006). Paper presented at the AERC International Conference held on Acceleratingin Tunis, Barn Africa's Development Five Years into the 21st Century, Tunisia, November 22-24, 2006.

4. Barmiro, O. A. (2007) Lead Paper at the 16th Engineering Assembly of Council for the Regulation of Engineering in Nigeria (COREN), held in Abuja, Nigeria, August 28-29, 2007 Cassava: Improving sustainability of farming systems, 31 March 2010: AnnekeFermont, a. fernlOnt@ci gar.org.

5. FAOSTAT, (2002). Food and Agriculture Organization, Statistical Data Base of the Food and Agricultural Organization (FAO). The United Nations, Rome, Italy.

6. Kolawole O.P. FAO, (2001) Food and Agricultural Organization, Product profile on cassava.

7. Ndaliman M.B., Design and Construction of a Pedal Operated Cassava Grinder, Unpublished Manuscript, 2006

* Corresponding Email: skolabello@yahoo.com 